\title{
Fertility Variation in Southern Thailand: 2002-2005
}

\author{
Pattama Arwae \\ Department of Mathematics and Computer Science \\ Faculty of Science and Technology, Prince of Songkla University, Pattani Campus \\ 181 Charoenpradit Rd., Rusamilae, Muaeng, Pattani, 94000 Thailand \\ E-mail: apateemo@bunga.pn.psu.ac.th \\ Chamnein Choonpradub (Corresponding author) \\ Department of Mathematics and Computer Science \\ Faculty of Science and Technology, Prince of Songkla University, Pattani Campus \\ 181 Charoenpradit Rd., Rusamilae, Muaeng, Pattani, 94000 Thailand \\ E-mail: cchamnein@bunga.pn.psu.ac.th \\ Nittaya McNeil \\ Department of Mathematics and Computer Science \\ Faculty of Science and Technology, Prince of Songkla University, Pattani Campus \\ 181 Charoenpradit Rd., Rusamilae, Muaeng, Pattani, 94000 Thailand \\ E-mail: nittaya@bunga.pn.psu.ac.th
}

\begin{abstract}
This study investigated variations in total fertility by religion and east-west location in Southern Thailand. Four provinces were selected for study (one mostly Muslim and one mostly non-Muslim). Data were obtained from birth certificates include month of birth, age group of mother, district of registration of birth and Muslim majority and Muslim minority locations from 2002-2005. Female population resident counts were obtained from the 2000 Thai Population and Housing Census. Districts were classified according to east-west location and percent Muslim. Logistic regression was used to model the effects of age group, region and period on the fertility in each 3-month quarter. Overall, the fertility rate of women where the percent Muslim was more than $80 \%$ was higher than that where the percent Muslim was less than $20 \%$. Muslim mothers on the east coast had a higher fertility rate than those on the west coast, but there is evidence that there fertility decreased over the study period and reached replacement level by 2006.
\end{abstract}

Keywords: Fertility rate, Demographic region, Logistic regression, Southern Thailand

\section{Introduction}

In Thailand the total fertility rate (the average number of children who would be born alive to a woman during her lifetime if she were to bear children at each age in accordance with the prevailing age-specific fertility rates) declined from 6.48 in 1960 to 1.82 in 2000 (Prachuabmoh and Mithranon 2003). The high fertility level in Thailand before the 1960s was facilitated by a pronatalist government policy which included bonuses for large families and incentives for early marriage. Government concern about the high rate of the population growth surfaced around 1960 but it was not until 1970 that an official population control policy was adopted.

Other countries in east and south-east Asia have experienced similar but less dramatic declines in fertility. During the period from 1975 to 2000 , China's estimated total fertility rate decreased from 3.57 to 1.80 , compared with decreases from 3.23 to 1.48 for South Korea, 2.07 to 1.59 for Singapore, and 1.91 to 1.34 for Japan (Gubhaju and Moriki-Durand 2003). Canada's total fertility rate reached 1.5 in 2000, while in the United States the fertility was 2.1. The fertility rates 
in Canada and the United States were different because of the minority populations (Hispanic immigrants) in the United States have a higher fertility rate than the minority population in Canada (Torrey and Haub, 2003).

Estimates of total fertility for Thailand in the year 2000 vary markedly by region, being lowest (1.17) in the Bangkok metropolitan area and highest (2.25) in the southern region comprising 14 provinces (Prachuabmoh and Mithranon 2003). Using data from two large national family health surveys in India, Mishra (2004) found that the total fertility rate declined from 3.39 in 1992-93 to 2.85 in 1998-99, with a difference between Muslim and Hindu total fertility rates. In the 1998-99 Indian survey the rate for Muslim residents was 3.58 compared to 2.77 for the Hindu population, and the author concluded that socioeconomic factors did not explain lower use of family planning and higher fertility among Muslims. One reason may be heavy reliance of India's family planning program on sterilization and Muslims' preference for temporary methods over sterilization. Another reason may be greater opposition to family planning among Muslims, which is indicated in surveys as their main reason for not currently using and not intending to use family planning in the future. Similar differences between Muslim and non-Muslim fertility in India, Malaysia, Philippines and Thailand were reported by Morgan et al (2002), finding that compared to non-Muslim women, Muslim women have more children, are more likely to desire additional children and are less likely to be using contraception when they desire no more children.

In Southern Thailand, where four of the 14 provinces have Muslim majorities, there is also evidence of substantial differences in fertility within the Muslim population. The 2000 Population and Housing Census of Thailand (National Statistical Office 2002) recorded substantial differences in growth rates between the Muslim and non-Muslim populations in the southern provinces. For example, in Pattani province the Muslim population (78\% in 1990) increased by $19 \%$ in the decade from 1990 to 2000 while at the same time the non-Muslim population increased by only $3 \%$, whereas the Muslim population of Krabi (36\% in 1990) also increased by $19 \%$ during the decade but the non-Muslim population increased by $23 \%$. Although these population changes are influenced to some extent by migration they are mainly determined by differences in fertility rates and consequent differences in age structures in the resident populations.

Based on a study of religion and reproduction in Southern Thailand, the National Statistical Office (1998) found that Islam exerts an important pronatalist influence on the attitudes and behaviour of Thai Muslims. However, the relationship between religion and reproduction is complex, and the different increases in population growth between Muslim populations in different provinces are a reflection of this complexity. Religion influences reproduction in interaction with ethnicity, culture and the status of minority groups.

Knodel et al (1998) examined the contrast between Muslim reproductive attitudes and behaviour in Thailand and those of Buddhists, focusing on the southern region and interpreting Muslim reproductive patterns from the perspectives of hypotheses invoked in the social demographic literature to explain links between religion and fertility. This study found that fertility among Buddhists had reached the replacement level with contraceptive use virtually universal, whereas Muslims in both the south and central regions had higher fertility levels and preferred to have more children than Buddhists.

This study aimed to investigate the pattern of fertility in Southern Thailand and attempt to account for variations in these patterns based on religion and east-west location. We selected four provinces for study, namely Trang, Satun, Songkla and Pattani.

\section{Materials and Methods}

\subsection{Data Source and Sample Selection}

We used cross-sectional data obtained from birth certificates in four southern Thai provinces, aggregated by month of birth, age of mother, and district of registration of birth from January 2002 to December 2005, together with female resident population counts obtained from the 2000 Thai Population and Housing Census (National Statistical Office 2002). The provinces were selected to include each of the east-west locations, Muslim majority ( $>50 \%$ Muslim) and Muslim minority ( $<50 \%$ Muslim). Trang (17\% Muslim) and Satun (68\% Muslim) are located on the west coast of the Malay peninsula and Songkla (23\% Muslim) and Pattani (82\% Muslim) are located on the east coast. Birth registration data for 2001 were excluded from the study because for the first seven months of 2001 the age of the father was recorded instead of that of the mother. Age distributions for the Muslim and non-Muslim populations in these provinces (based on the 2000 population census) are quite different (Figure 1), with the Muslim populations much younger than those of the non-Muslim populations, particularly in Pattani.

\subsection{Variables}

The birth certificate form contains the date and district of registration of the birth and the age of the mother. The district of registration is the district where the baby is born, which may not be the same as the district of residence of the mother. The age of the mother in years, is classified as 20 or less, $21-25,26-30,31-35,36-40,41-45$, and 46 or more. 


\subsection{Data Analysis}

The data records comprised the numbers of live births $B_{i j t}$ classified by registration district $i$, age-group and month $t$, and the estimated populations of women in the age-group. We estimated this population using the formula

$$
P_{j t}=p_{t} N_{j}+\left(\tilde{1} p_{t}\right) N_{j 1}
$$

where $N_{j}$ is the female population recorded at the 2000 Population Census in age group $j$ (where $j=1$ for $0-4, j=2$ for $5-9$, etc.), which is one year less than the reported age group of the mother, and $p_{t}$ is the proportion of the 5-year period elapsed from January 2001 until month $t$. This calculation synchronizes the Census population age groups with those used in the birth registration form.

We classified the 45 districts into 8 regions according to east-west location and percent Muslim using four groups (below 20\%, 20-50\%, 51-80\%, more than 80\%) as shown in Figure 2.

\subsection{Statistical Methods}

In the preliminary analysis we computed the total fertility $(T F)$ for each year and region $i$ using the standard demographic formula (Pollard et al 1974) for 5-year age groups, namely

$$
T F_{i}=\sum_{j=4}^{10}\left(5 \sum_{t} B_{i j t} / \frac{1}{12} \sum_{t} P_{i j t}\right),
$$

where $t$ is summed over all months within the specified year. Note that the contribution from each of the seven age groups $(j=4,5, \ldots, 10)$ is 5 (the width of the age group in years) times the total number of births in the 12-month period of interest divided by the average number of women in the corresponding age group.

In further analysis logistic regression (Kleinbaum and Klein 2002) was used to model the effects of age group, region and period on the fertility in each 3-month quarter of a year. The observed fertility is the proportion that a woman in a specified age group registers a birth in a specified region and quarter. Asymptotic results using statistical theory provide estimates based on maximum likelihood fitting of the model, together with confidence intervals and p-values for testing relevant null hypotheses (see, for example, Kleinbaum \& Klein, 2002).

Goodness-of-fit of model

For each cell corresponding to a combination of nominal determinants, the Pearson

residual is defined as

$$
z=\frac{p-\hat{p}}{\sqrt{\hat{p}(1-\hat{p}) / n}},
$$

where $p$ is the proportion of outcomes observed in the cell, $\hat{p}$ is the corresponding probability given by the model, and $n$ is the total number of cases in the cell. The goodness-of-fit of the model can be assessed visually by plotting these z-values against corresponding normal scores. The fit is adequate if the points in this plot are close to a straight line with unit slope. A p-value for the goodness-of-fit is obtained by subtracting the deviance associated with the saturated model from the model deviance and comparing this difference $R_{g}$ with a chi-squared distribution having degrees of freedom equal to $\tilde{n_{g}} m$, where $n_{g}$ is the number of cells and $m$ is the number of parameters in the model.

\section{Results}

\subsection{Preliminary Analysis}

Table 1 shows the total fertility $(T F)$ and its age-specific components based on registered births in all four provinces for years 2002-2005. This indicates that the overall fertility in the four provinces appears to be near replacement level.

The estimates given in Table 2 are biased because many women move from their district of residence to give birth in a hospital located in another region where the birth is subsequently registered, so calculating the birth rate in a region based on the number of mothers resident in the region (as in Table 2) yields rates that are biased upward or downward, depending on this flow of movement.

Estimates of the net movement of mothers between regions is shown in Table 3, which lists the numbers of registered births in each region on the bottom line and the population in these regions aged 0-4 years in the right-hand column. The numbers in the body of the table are estimates of the numbers of births registered to residents of the regions, obtained as follows. First, we estimate the total number of births to residents of each region in the 5-year period from 2001 to 2005 by reducing the populations in the age group 0-4 in the 2000 Population Census by the constant $3.05 \%$, the factor needed to match the total number of registered births in the four provinces. If this total is less than the number 
of births registered in the region, we simply transfer it to its corresponding diagonal cell in the table. Next, we fill in the remaining diagonal cells using the corresponding totals in the bottom row. Finally, we fill in as many remaining cells as are necessary to make all the row and column totals match, based on assumptions about where mothers are likely to go if they register their births outside their region of residence.

The information in Table 3 forms the basis for recalculating total fertility, by replacing the denominators used to obtain the estimates in Table 2 by weighted sums using the row proportions given in Table 3 . Let $P_{i j t}$ denote the number of women resident in region $i$ (ordered as in the top row of Table 2) and age group $j$ in month $t$. Then the adjusted estimate of the number of mothers in age-group $j$ in month $t$ for the east coast region with percent Muslim less than 20\% $(i=5)$, for example, is given by the formula $0.258 P_{2 j \mathrm{t}}+0.170 P_{4 j t}+P_{5 j t}+0.497 P_{6 j t}+0.004 P_{7 j \mathrm{t}}+0.130 P_{8 j \mathrm{t}}$. Using the method described in Section 2.3 to estimate the total numbers of women resident in any specified month in 2002-2005 based on the numbers of women recorded in the 2000 population census, we thus obtain the numbers of women (in all seven age groups) resident in the eight regions in January 2002 (say) as $P_{1}=108,767, P_{2}=219,004, P_{3}=55,578, P_{4}=94,040, P_{5}$ $=49,021, P_{6}=110,448, P_{7}=27,714$ and $P_{8}=107,117$, respectively. Substituting these values into the above formula, we estimate the total number of women giving birth in the region to be 190,440 . In the same way, estimates may be obtained of the numbers of women from each age group giving birth to babies registered in each region in each month, and these numbers provide appropriate denominators for obtaining relatively unbiased estimates of the total fertility.

\subsection{Estimation of fertility using logistic regression model}

Table 5 shows the result of fitting a logistic regression model to the number of registered births in a month by region, age group and period. The denominators (the numbers of women giving birth) are estimated using the method described above.

The result of fitting a logistic regression model to the number of registered births in a month by region, age group and period is statistically significant. However, the fit is inadequate with Residual deviance 902.3 and 381 degrees of freedom. This due to the very large data set (the population data). The model contains coefficients for each combination of age group and region (56 parameters), as well as 8 parameters describing the change from 2002-2003 to 2004-2005 for each region, and a further 3 parameters describing a quarterly seasonal effect.

The coefficients obtained from the model are plotted in Figure 3. It can be seen more clearly from this plot that the fertility rates of the mother in both east and west regions where there is a Muslim majority are higher than where there is a Muslim minority. Fertility among Muslims majority was higher on the east coast.

\section{Conclusion and Discussion}

In this study, data was obtained from birth certificates in four southern Thai provinces, aggregated by month of birth, age of mother, and district of registration of birth from January 2002 to December 2005, together with female resident population counts obtained from the 2000 Thai Population and Housing Census (National Statistical Office 2002). We used graphical and statistical methods to investigate the pattern of fertility in each period and region, and used logistic regression to fit a model for predicting the effects of age group, region and period on the fertility in each 3-month quarter of a year.

Our study found that the fertility of Muslim mothers is higher than that of non-Muslim mothers. This result agrees with other studies in India, Malaysia, Philippines and Thailand (Mishra, 2004; Morgan et al, 2002; Knodel et al, 1998). We also found that the fertility rate in all regions continuously declined and fell below replacement level. The results of this study agree with Prachuabmoh and Mithranon, 2003; Gubhaju and Moriki-Durand, 2003; Atoh M. et al, 2004; Chayovan and Tsuya, 2003. In Non-Muslim regions, the fertility rate sharply declined while in Muslim regions it only slightly declined.

Many women travel from their district of residence to give birth in a hospital located in another region where the birth is subsequently registered. Calculation of the birth rate in a region based on the number of mothers resident in the region may therefore yield birth rates that are biased. Thus, we estimate the total number of births to residents of each region in the 5-year period from 2001 to 2005 by reducing estimates of the number of births, by using the populations in the age group 0-4 in the 2000 Population Census.

\section{Acknowledgement}

We would like to express our gratitude to Emeritus Prof. Don McNeil for his great guidance.

\section{References}

Atoh M., Kandiah, V., \& Ivanov, S. (2004). The Second Demographic Transition in Asia: Comparative Analysis of the Low Fertility Situation in East and South-East Asian Countries. The Japanese Journal of Population, 12(1), $42-75$. 
Chayovan, N., \& Tsuya, O. N. (2003). Demographic Situation in Thailand: An Updated from the 2001 ECODDF Survey. A paper prepared for the Conference on COE Project on Asian Financial Crisis and Its Macroeconomic Responses, Keio University, Japan.

Gubhaju, B., \& Moriki-Durand, Y. (2003). Below-replacement fertility in East and Southeast Asia: consequences and policy responses. J Pop Research, 20(1)-1-18.

Kleinbaum, D., \& Klein, M. (2002). Logistic Regression - a Self-learning Text. ( $2^{\text {nd }}$ ed). New York: Springer-Verlag.

Knodel, J., Soottipong-Gray, R., Sriwatcharin, P., \& Peracca, S. (1998). Religion and reproduction: Muslims in Buddhist Thailand. Report No 98-417, Population Studies Center. University of Michigan.

Mishra, V. (2004). Muslim/non-muslim differentials in fertility and family planning in India. Working Paper No 112, Population and Health Series, East-West Center.

Morgan, SP., Stash, S., Smith, HL., \& Mason, KO. (2002). Muslim and non-Muslim differences in female autonomy and fertility: evidence from four Asian countries. Population \& Development Review, 28(3), 515-537.

National Statistical Office. (1998). Religion and Reproduction in Southern Thailand. Statistical Data Bank and Information Dissemination Division.

National Statistical Office. (2002). The 2000 Population and Housing Census, SouthernRegion. [Online] Available: http://webhost.nso.go.th:9999/nso/project/search/index.jsp (Jun, 10, 2005)

Pollard, AH., Yusuf, F., \& Pollard, GN. (1974). Demographic Techniques. Pergamon Press: Australia.

Prachuabmoh, V., \& Mithranon, P. (2003). Below-replacement fertility in Thailand and its policy implications. J Pop Research, 20(1), 35-50.

Torrey, B., B., \& Haub, C. (2003). Diverging Mortality and Fertility Trends: Canada and the United States. [Online] Available: http://www.prb.org/Article/2003/DiergingMortalityandFertilityTrendsCanadaandtheUnitedStaes (Mar, 19, 2009) 
Table 1. Total fertility and age-specific components based on births from 4 provinces

\begin{tabular}{l|llllllll}
\multirow{2}{*}{ year } & \multicolumn{2}{l}{ age group } & & & & \multicolumn{2}{c}{} & \multirow{2}{*}{$T F$} \\
& $15-19$ & $20-24$ & $25-29$ & $30-34$ & $35-39$ & $40-44$ & $45-49$ & \\
2002 & 0.248 & 0.481 & 0.523 & 0.394 & 0.212 & 0.066 & 0.023 & 1.946 \\
2003 & 0.262 & 0.459 & 0.507 & 0.383 & 0.211 & 0.064 & 0.021 & 1.907 \\
2004 & 0.285 & 0.459 & 0.521 & 0.389 & 0.206 & 0.067 & 0.015 & 1.943 \\
2005 & 0.299 & 0.458 & 0.526 & 0.387 & 0.202 & 0.056 & 0.010 & 1.938
\end{tabular}

Table 2. Total fertility by demographic region based on birth registrations

\begin{tabular}{|c|c|c|c|c|c|c|c|c|}
\hline \multirow[b]{2}{*}{ \% Muslim } & \multicolumn{4}{|c|}{ west coast } & \multicolumn{4}{|c|}{ east coast } \\
\hline & $<20$ & $20-49$ & $50-79$ & $80+$ & $<20$ & $20-49$ & $50-79$ & $80+$ \\
\hline 2002 & 2.050 & 1.126 & 2.187 & 1.432 & 2.218 & 0.942 & 2.202 & 2.424 \\
\hline 2003 & 2.053 & 0.987 & 1.996 & 1.450 & 2.255 & 0.880 & 2.141 & 2.337 \\
\hline 2004 & 2.136 & 0.951 & 2.234 & 1.336 & 2.391 & 0.965 & 2.150 & 2.116 \\
\hline 2005 & 2.288 & 0.966 & 2.181 & 1.206 & 2.423 & 0.878 & 2.148 & 2.016 \\
\hline
\end{tabular}

Table 3. Estimates of numbers of births registered in 8 demographic regions classified by region of residence of mother

\begin{tabular}{|c|c|c|c|c|c|c|c|c|c|c|}
\hline Region & west & west & west & west & east & east & east & east & estimate & $0-4$ in \\
\hline $\begin{array}{l}\% \text { Musli } \\
\mathrm{m}\end{array}$ & $0-19$ & $20-49$ & $50-79$ & $80+$ & $0-19$ & $20-49$ & $50-79$ & $80+$ & of total & \\
\hline W 0-19 & 30611 & & & & & & & & 30611 & 31574 \\
\hline W20-49 & 4155 & 8988 & & & 4566 & & & & 17709 & 18262 \\
\hline W 50-79 & & & 14850 & & & & & & 14850 & 15317 \\
\hline W $80+$ & & & 1661 & 5891 & 1548 & & & & 9100 & 9386 \\
\hline E $0-19$ & & & & & 51127 & & & & 51127 & 52735 \\
\hline E $20-49$ & & & & & 13820 & 13961 & & & 27781 & 28655 \\
\hline E $50-79$ & & & & & 156 & & 37072 & & 37228 & 38399 \\
\hline E $80+$ & & & & & 5682 & & & 37969 & 43651 & 45024 \\
\hline tal & 34766 & 8988 & 16511 & 5891 & 76899 & 13961 & 37072 & 37969 & 232057 & 239356 \\
\hline
\end{tabular}

Table 4. Total fertility by demographic region based on birth registrations and numbers of mothers in denominator adjusted for region of registration

west coast east coast

\begin{tabular}{|c|c|c|c|c|c|c|c|c|c|}
\hline$\%$ Muslim & & $<25$ & $25-49$ & $50-79$ & $80+$ & $<25$ & $25-49$ & $50-79$ & $80+$ \\
\hline & 2002 & 1.825 & 2.217 & 1.976 & 2.213 & 1.613 & 1.873 & 2.211 & 2.786 \\
\hline & 2003 & 1.827 & 1.943 & 1.803 & 2.242 & 1.634 & 1.750 & 2.150 & 2.686 \\
\hline & 2004 & 1.900 & 1.873 & 2.017 & 2.065 & 1.725 & 1.918 & 2.159 & 2.432 \\
\hline & 2005 & 2.034 & 1.901 & 1.967 & 1.865 & 1.741 & 1.745 & 2.157 & 2.318 \\
\hline
\end{tabular}


Table 5. Results of logistic model to outcome monthly birth rate

\begin{tabular}{|c|c|c|c|c|}
\hline Determinant & Coefficient & St Error & z-value & $\mathrm{p}$-value \\
\hline Constant & -5.3715 & 0.0165 & -325.64 & 0.0000 \\
\hline Age-group.Region: & baseline: & 15-19. west $<20$ & & 0.0000 \\
\hline $15-19$. east $<20$ & -0.1945 & 0.0198 & -9.85 & 0.0000 \\
\hline 15-19.west20-49 & 0.2870 & 0.0335 & 8.58 & 0.0000 \\
\hline 15-19. east20-49 & 0.2371 & 0.0281 & 8.43 & 0.0000 \\
\hline 15-19.west50-79 & -0.0186 & 0.0283 & -0.66 & 0.5114 \\
\hline 15-19.east50-79 & -0.0259 & 0.0230 & -1.13 & 0.2605 \\
\hline 15-19.west80+ & 0.2941 & 0.0390 & 7.55 & 0.0000 \\
\hline 15-19.east80+ & 0.0313 & 0.0231 & 1.35 & 0.1756 \\
\hline 20-24.west $<20$ & 0.5246 & 0.0188 & 27.88 & 0.0000 \\
\hline $20-24$.east $<20$ & 0.3276 & 0.0184 & 17.79 & 0.0000 \\
\hline 20-24.west20-49 & 0.6892 & 0.0301 & 22.87 & 0.0000 \\
\hline 20-24.east20-49 & 0.5184 & 0.0263 & 19.72 & 0.0000 \\
\hline 20-24.west50-79 & 0.4906 & 0.0255 & 19.26 & 0.0000 \\
\hline 20-24.east50-79 & 0.6266 & 0.0206 & 30.40 & 0.0000 \\
\hline 20-24.west $80+$ & 0.6075 & 0.0359 & 16.93 & 0.0000 \\
\hline 20-24.east $80+$ & 0.7282 & 0.0207 & 35.25 & 0.0000 \\
\hline 25-29. west $<20$ & 0.6683 & 0.0186 & 36.02 & 0.0000 \\
\hline $25-29$. east $<20$ & 0.5286 & 0.0181 & 29.21 & 0.0000 \\
\hline 25-29.west20-49 & 0.6387 & 0.0312 & 20.47 & 0.0000 \\
\hline 25-29. east20-49 & 0.4369 & 0.0271 & 16.15 & 0.0000 \\
\hline 25-29.west50-79 & 0.6377 & 0.0250 & 25.54 & 0.0000 \\
\hline 25-29.east50-79 & 0.6637 & 0.0207 & 32.13 & 0.0000 \\
\hline 25-29.west $80+$ & 0.6282 & 0.0365 & 17.22 & 0.0000 \\
\hline 25-29.east $80+$ & 0.8184 & 0.0207 & 39.53 & 0.0000 \\
\hline $30-34$.west $<20$ & 0.2125 & 0.0201 & 10.55 & 0.0000 \\
\hline $30-34$.east $<20$ & 0.2150 & 0.0187 & 11.50 & 0.0000 \\
\hline 30-34.west20-49 & 0.2236 & 0.0357 & 6.26 & 0.0000 \\
\hline 30-34.east20-49 & 0.0719 & 0.0304 & 2.37 & 0.0179 \\
\hline 30-34.west50-79 & 0.2335 & 0.0275 & 8.50 & 0.0000 \\
\hline 30-34.east50-79 & 0.4651 & 0.0215 & 21.65 & 0.0000 \\
\hline 30-34.west80+ & 0.4167 & 0.0398 & 10.46 & 0.0000 \\
\hline 30-34.east $80+$ & 0.7391 & 0.0213 & 34.75 & 0.0000 \\
\hline 35-39.west $<20$ & -0.6542 & 0.0257 & -25.43 & 0.0000 \\
\hline 35-39. east $<20$ & -0.5902 & 0.0212 & -27.78 & 0.0000 \\
\hline 35-39.west20-49 & -0.4097 & 0.0458 & -8.94 & 0.0000 \\
\hline 35-39. east20-49 & -0.4765 & 0.0376 & -12.66 & 0.0000 \\
\hline 35-39.west50-79 & -0.3608 & 0.0335 & -10.76 & 0.0000 \\
\hline 35-39.east50-79 & -0.0160 & 0.0239 & -0.67 & 0.5045 \\
\hline 35-39.west80+ & -0.1177 & 0.0509 & -2.31 & 0.0206 \\
\hline 35-39.east $80+$ & 0.4202 & 0.0231 & 18.19 & 0.0000 \\
\hline $40-44$.west $<20$ & -1.9960 & 0.0454 & -44.01 & 0.0000 \\
\hline $40-44$. east $<20$ & -2.1515 & 0.0346 & -62.24 & 0.0000 \\
\hline 40-44.west20-49 & -1.5471 & 0.0788 & -19.62 & 0.0000 \\
\hline 40-44.east20-49 & -1.4933 & 0.0601 & -24.84 & 0.0000 \\
\hline 40-44.west50-79 & -1.4900 & 0.0551 & -27.06 & 0.0000 \\
\hline 40-44.east50-79 & -1.0513 & 0.0342 & -30.74 & 0.0000 \\
\hline 40-44.west80+ & -0.9763 & 0.0788 & -12.39 & 0.0000 \\
\hline 40-44.east $80+$ & -0.5259 & 0.0319 & -16.49 & 0.0000 \\
\hline $45-49$. west $<20$ & -3.9852 & 0.1289 & -30.92 & 0.0000 \\
\hline $45-49$. east $<20$ & -4.3331 & 0.0999 & -43.37 & 0.0000 \\
\hline 45-49.west20-49 & -2.2887 & 0.1229 & -18.62 & 0.0000 \\
\hline 45-49.east20-49 & -2.4921 & 0.1043 & -23.88 & 0.0000 \\
\hline 45-49.west50-79 & -2.5537 & 0.0985 & -25.94 & 0.0000 \\
\hline 45-49.east50-79 & -2.2625 & 0.0625 & -36.21 & 0.0000 \\
\hline 45-49.west80+ & -2.1703 & 0.1523 & -14.25 & 0.0000 \\
\hline 45-49.east $80+$ & -1.5744 & 0.0530 & -29.68 & 0.0000 \\
\hline
\end{tabular}


Table 5. Results of logistic model to outcome monthly birth rate (continue)

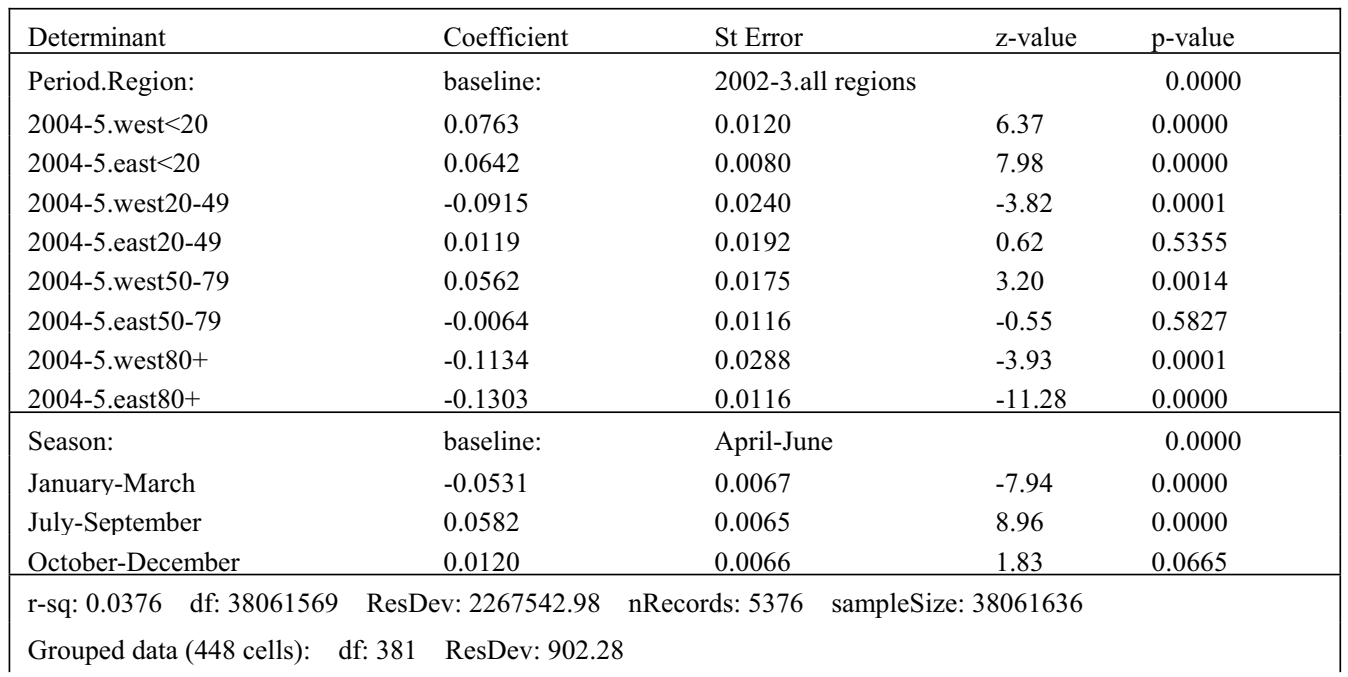

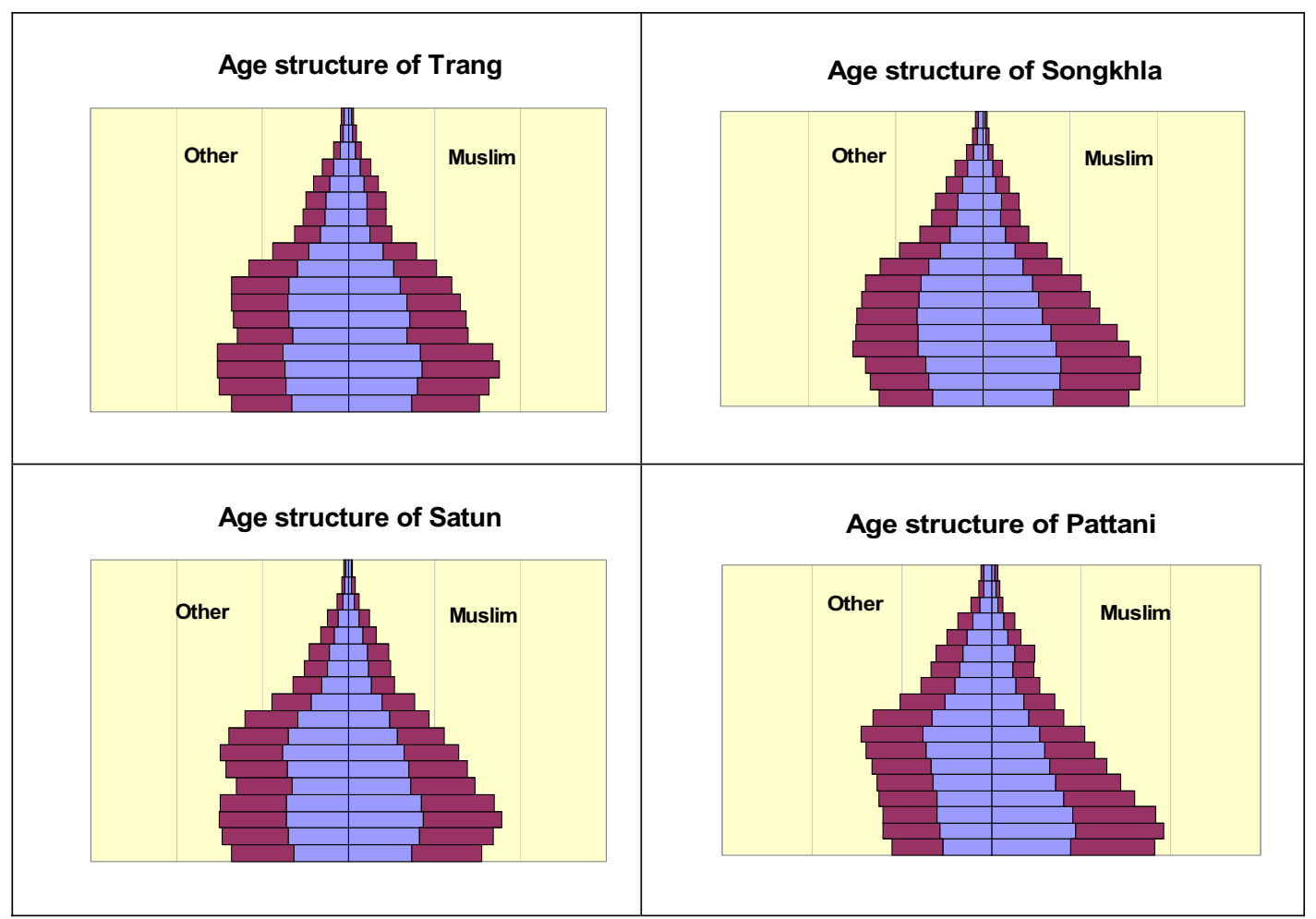

Figure 1. Age pyramids for Muslim and non-Muslim populations in 4 provinces 


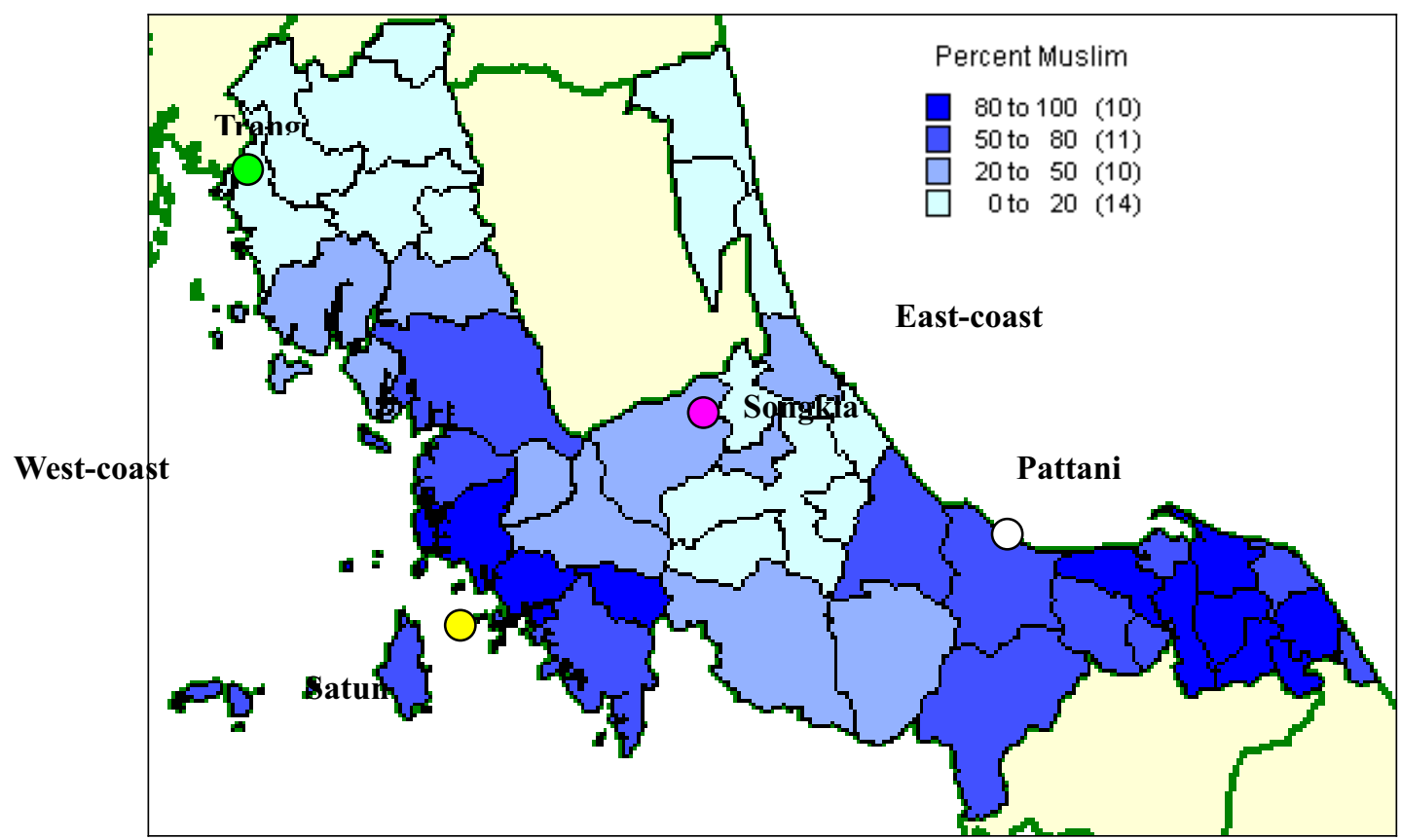

Figure 2. Classification of districts in 4 southern Thai provinces by percent Muslim

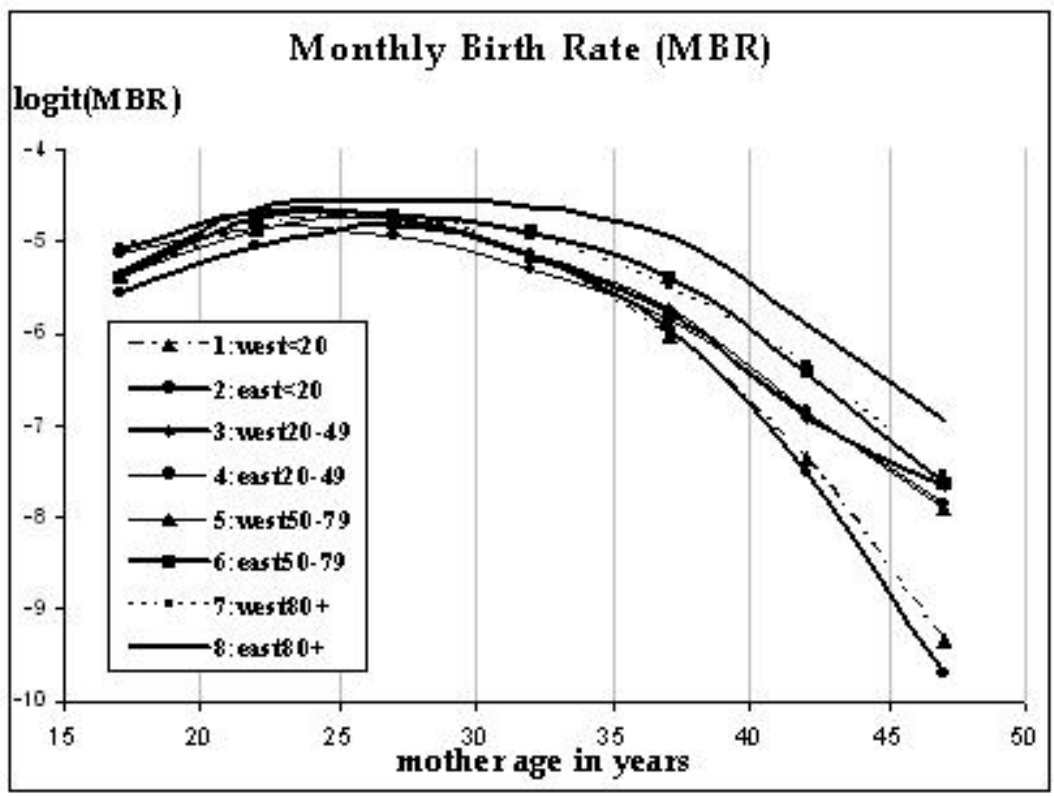

Figure 3. Logits of monthly birth rates based on fitted logistic model 